\title{
In memory of James F. Crow (1916-2012), a life dedicated to population genetics; with an updated list of his publications
}

\author{
Paulo A. Otto \\ Departamento de Genética e Biologia Evolutiva, Instituto de Biociências, \\ Universidade de São Paulo, São Paulo, SP, Brazil.
}

Professor James ("Jim") F. Crow (Figure 1) died on January 4, 2012, of natural causes in Madison, Wisconsin, two weeks before his $96^{\text {th }}$ birthday. Born in Phoenixville (Pennsylvania) on January 18, 1916, Professor Crow earned a B.A. in Chemistry and Biology from Friends University in 1937 and a Ph.D. in Zoology at the University of Texas in Austin under the supervision of Professor J. T. Patterson. His dissertation was on hybridization and isolating mechanisms in the mulleri group of Drosophila.

From 1941 to 1948 he taught at Dartmouth College (Hanover, New Hampshire) before moving to the University of Wisconsin (UW) in Madison, where he worked formally from 1948 as an assistant professor until his retirement in 1986 as a senior distinguished research professor and afterwards as a retired UW emeritus professor. Two weeks before he passed away he was at his UW office working on a new paper.

At UW he was the main person responsible for the creation of the Laboratory of Genetics and for maintaining its high standards. Besides attracting to it an exceptionally competent group of geneticists that transformed the department into a center of international excellence (in the sixties it was considered the best genetics center in the world), he was during many years head and chair of the Genetics and Medical Genetics departments and acting dean of the Medical School. He was a member of the National Academy of Sciences, National Academy of Medicine, American Philosophical Society, American Academy of Arts and Sciences, World Academy of Art and Science, Genetics Society of America, American Society for Human Genetics, Royal Society (England), Japan Academy, Genetics Society of Japan, and Wisconsin Academy of Sciences, Arts and Letters. He was also an accomplished musician, having had formal education and training in violin and piano playing; he played viola at the Madison Symphony Orchestra, to which he belonged from 1949 to 1987 (president, 1984-1986). He was also a former president of the Madison Civic Association. It was when studying music that he met his lifelong wife Ann Crockett Crow (then a clarinet student), who died

Send correspondence to Paulo A. Otto. Departamento de Genética e Biologia Evolutiva, Instituto de Biociências, Universidade de São Paulo, Cidade Universitária, Rua do Matão 277, 05422-970 São Paulo, SP, Brazil. E-mail: otto@usp.br. in 2001. He is survived by three children, six grandchildren, and two great-grandchildren.

Given his expertise in several areas of genetics, especially population genetics, human genetics, and radiation biology, since 1955 he was a scientific advisor to the National Academy of Sciences and the Congress of the United States, acting in Official Committees (in many as chair) on themes such as effects, risks, and impact of ionizing radiation and chemical mutagens, nuclear and alternative energy systems, and standardization of forensic genetic procedures. He had almost uncanny didactic and teaching skills and was regularly consulted on several issues dealing with undergraduate and graduate education policies, both at national as well as international levels.

He wrote three fabulous textbooks, "Genetics Notes", "An Introduction to Theoretical Population Genetics", and "Basic Concepts in Population, Evolutionary and Quantitative Genetics"; more recently, he published, together with

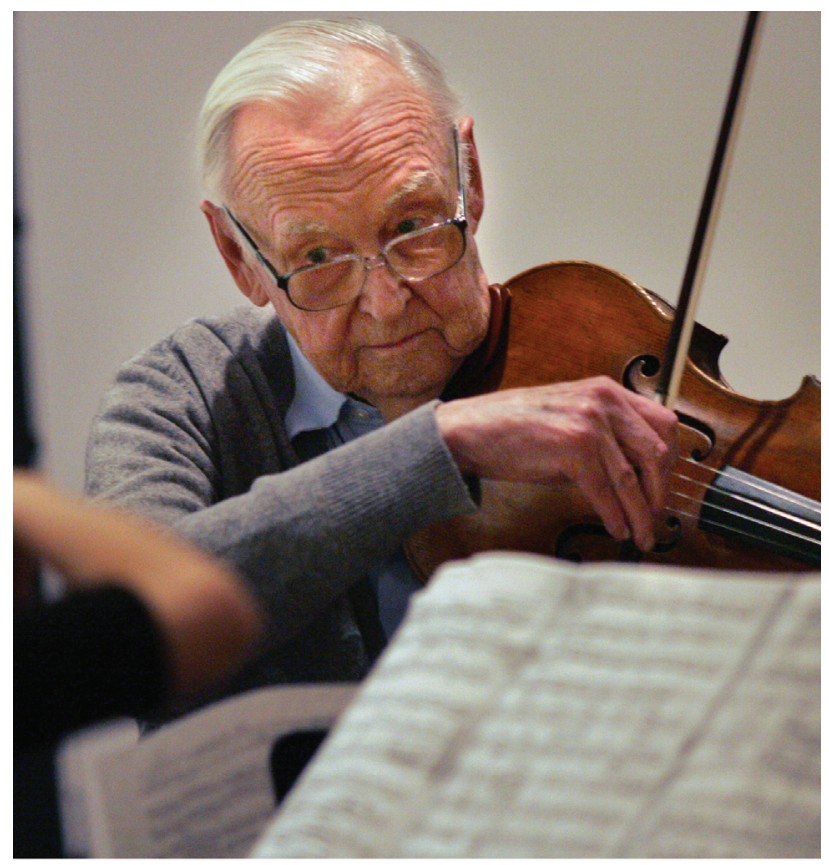

Figure 1 - James F. Crow on a concert he organized on occasion of his $90^{\text {th }}$ birthday. (Photograph by Craig Schreiner, reproduced with permission from Wisconsin State Journal). 
Professor W.F. Dove, a collection of 141 papers (24 written by him) dealing with the history and development of genetics, and published in the section "Perspectives on Genetics" of the journal Genetics they edited from 1987 to 1998.

His book "Genetics Notes" was published in several editions and translated into several languages (including one in Portuguese, published in Brazil and translated by Professor Henrique Krieger). Apparently unpretentious and intended for teaching undergraduate students, this book is so good and its language so clear that, so the story goes, its use was forbidden by a professor of a well known university course on the grounds that, from the many different sources recommended by him, students would consult Crow's book only.

His book on population genetics, written in collaboration with Professor Motoo Kimura and published in 1970 (a reprint version is still available), is justly considered not only a true classic in the field but also the standard textbook on the subject. It is a comprehensive text where clarity of explanation and mathematical depth are masterly blended in a direct, simple, and harmonic manner.

The third book listed, "Basic Concepts in Population, Evolutionary and Quantitative Genetics" is another of Jim's didactic jewels, practically an updated, simplified and abridged version of the second book, intended for a broader set of students, including those with a more basic knowledge of mathematics and statistics.

Alone or in collaboration with his many students, post-docs and colleagues he wrote more than 300 scientific articles (Supplementary Material, Detailed bibliography). Most if not all of these articles played an important role for the coming of age of population genetics at a time when the field was of interest merely to a small privileged group of specialists. Its applications were not so obvious and important as today, after its revival due to both the availability of a reliable mass of data, as well as the broad amount of new genetic details brought about by the current explosion of molecular genetics knowledge.

As Professor Joseph Felsenstein wrote in a recent obituary (Felsenstein J. - James F. Crow (1916-2012), http://pandasthumb.org/archives/2012/01/james-f-crow-19. html, "Jim's many papers included major work on mutational load and other forms of genetic load, clarification of the concepts of inbreeding and variance effective population number, and expanding on R.A. Fisher's and H.J. Muller's theory of the evolutionary advantage of recombination. In the 1950s and early ' 60 s he was a major participant in the debate over genetic variation in natural populations, arguing against Theodosius Dobzhansky's view that attributed it largely to balancing selection. With Motoo Kimura, in 1964 he derived the expected heterozygosity brought about by neutral mutation, and he played a major role in assisting Motoo Kimura in effectively presenting his case for neutral mutation".

Unlike many contemporary population geneticists who were more pragmatic, bordering on opportunism, in drifting, in order to guarantee their successful scientific and academic careers, to fields that could be circumscribed as "molecular population genetics" and "statistical population genetics", Professor Crow was able to contribute to the field through keeping a balanced distance from ultraspecialized and complicated subjects thanks to his comprehensive and in-depth knowledge of high-level basic population genetic issues, his almost uncanny capacity of explaining everything in a straightforwardly clear way, and his thorough background on mathematical and statistical methods commonly used in population genetics analysis. This is exceptional for someone who had no formal education in the area; when young and following the advice from Professor W.S. Stone at Texas University he merely took some isolated advanced courses on calculus and probability.

On several occasions Professor Crow declared that his main legacy was the unusually good group of graduate students and post-docs he had, "many of which have gone on to make names for themselves in genetics", as he put it on a videotaped conversation with Professor Hartl of Harvard University [for a complete list, see Hartl D.L. (2011) James F. Crow and the art of teaching and mentoring. Genetics 189:1129-1133]. This list of 52 ex-students and post-docs has been described on many occasions as a kind of "who's-who in population genetics" and includes scientific leaders such as Newton E. Morton, Motoo Kimura, Joseph Felsenstein, and Daniel L. Hartl, just to name a few among many who excelled in genetics.

As a personal and final note, I would like to express my affection and admiration for Jim Crow. Besides being a true scientific leader and certainly the best population geneticist after the founding era of the field by trio FisherHaldane-Wright, he was a truly good human being, devoid of vanity, prejudice, selfishness, and envy, who continually inspired us all with his genuine enthusiasm. Those of us who were privileged to know him personally, to work with him and learn from him, will greatly miss him.

\section{Supplementary Material}

The following online material is available for this article:

Detailed bibliography of Prof. Dr. James F. Crow, updated to 2010, listing some 400 articles, in-depth book reviews, book chapters, and high level genetic reviews for the non-specialist.

This material is made available as part of the online article from http://www.scielo.br.gmb. 